\title{
The effects of bimodal grain size distributions on the work hardening behavior of a TRansformation-TWinning Induced Plasticity steel
}

\author{
H. Eskandari Sabzi, A. Zarei Hanzaki*1, H.R. Abedi, R. Soltani, J.J. Roa, A.Mateo \\ Hot Deformation \& Thermomechanical Processing of High Performance Engineering Materials Lab, \\ School of Metallurgy and Materials Engineering, College of Engineering, University of Tehran, Tehran, \\ Iran
}

Departament de Ciència dels Materials I Enginyeria Metal. lúrgica, Universitat Politècnica de Catalunya ,Avda. Diagonal647, 08028 Barcelona, Spain

\begin{abstract}
The effects of bimodal grain size distributions on the mechanical properties of a newly developed TRansformation-TWinning induced plasticity (TRIP/TWIP) steel were investigated. The microstructures with different levels of bimodal grain size distributions were achieved through rolling at 1000,1100 and $1200^{\circ} \mathrm{C}$ where the restoration processes (in particular recrystallization) could be occurred at different rates. The results indicated that the bimodal distribution parameter was increased by raising the rolling temperature and lowering the thickness reduction. In addition, the room temperature strength and ductility were higher for the materials rolled at higher temperatures, where the level of bimodal grain size distributions (bimodality) was greater. This was justified considering the higher possibility of strain induced transformation and twinning in coarser grains than that of finer ones; this in fact would dictate the material work hardening potential during subsequent tensile deformation. For the material rolled at $1000^{\circ} \mathrm{C}$, where the grain size distributions were more homogeneous and the level of bimodal distributions was low, the austenite to martensite transformation during tensile deformation at room temperature was the prevailing mechanism to induce the plasticity. In contrast, in the materials rolled at 1100 and $1200^{\circ} \mathrm{C}$ the mechanical twinning came into action thereby a rapid hardening region was recognized in their work hardening behavior. These effects were correlated to the length of work hardening region (dictated by twinning), and the magnitude of hardening rate (controlled by transformation of austenite to $\alpha^{\prime}$ martensite).
\end{abstract}

\footnotetext{
${ }^{*}$ Corresponding author. Tel.: +98 21 82084116; fax: +98 2188006076.

E-mail address: zareih@ut.ac.ir (A. Zarei-Hanzaki).
} 
Keywords: Transformation-twinning induced plasticity steel; Mechanical twinning; Martensitic transformation; Bimodality; Work hardening behavior

\section{Introduction}

In general, the ultra-fine grained steels with homogenized grain size distribution exhibit high strength and desired but not high ductility at room temperature. The latter is attributed to the lack of optimized work hardening behavior during plastic deformation [1-3]. The development of bimodal grain size distribution, which simultaneously consists of coarse and fine grains mixture, was introduced as a key concept to improve the strength and formability of the ferrous and nonferrous alloys $[4,5]$. Bimodal grain structures, owing to the high work hardening capacity of coarser grains along with the strengthening ability of finer ones, exhibit superior combination of strength and ductility [6]. However, based on the up to date literature, a set of systematic studies is required to understand the effects of bimodal grain size distribution on the subsequent microstructural evolution and mechanical properties. This plays more important role in the case of advanced high strength steels where the dominant deformation mechanisms are highly dictated by the grain size $[7,8]$.

The high manganese transformation and twinning induced plasticity (TRIP/TWIP) steels, owing to their exceptional combination of strength, ductility and strain hardening potential, have been the subject of many industrials and academic researches [9-11]. The mechanical properties of these steels are effectively determined by their chemical compositions and stacking fault energy (SFE). The latter in fact controls the alloy strain hardening capability through strain induced $\gamma \rightarrow \varepsilon$ and $\gamma \rightarrow \alpha^{\prime}$ martensite transformations and deformation twinning [12-16]. The results of previous 
researches indicate that the TRIP and TWIP effects might occur simultaneously where the SFE lays between 18 to $22 \mathrm{~mJ} / \mathrm{m}^{2}$; the TRIP and TWIP would be individually triggered by SFEs lower or higher than the aforementioned range, respectively. In addition, the strength and ductility would be higher where the martensite transformation and twinning occur concurrently during deformation [17-22]. The martensite platelets and mechanical twins act as planar obstacles to dislocation glide during further straining. These planar defects may lead to an excessive work hardening and a delayed necking thereby resulting in greater uniform elongation [23-26]. In this regard, Ding et al [17] correlated the various strain hardening stages of an advanced austenitic steel to the sequential occurrence of tripping and twipping. Furthermore, the capability of any microstructure to twipping and tripping is significantly influenced by the stability of austenite $[27,28]$, the type of present constraint $[27,28]$, the value of stacking fault energy, and obviously the grain size and its morphology [9,29].

In order to assist industrializing the manufacturing processes of these advanced high strength steels, applying a proper thermomechanical processing cycle is promising not only to break the cast structure down and simultaneously shape the material, but as an intermediate process to refine the grain size and optimize the microstructures. The results of numerous investigations conducted in this area show that the recrystallization phenomena, in particular the dynamic recrystallization one, would act as the main restoration mechanism and control the microstructural evolution in different hot working conditions [30,31]. However, as is well established, a bimodal grain size structure (which holds a mixture of fine and coarse grains) would be developed if the deformation were significantly inhomogeneous,. Furthermore, the grain size and its distribution significantly affect the martensite transformation and the frequency of twinning thereby dictating the work hardening behavior during subsequent deformation [32-36]. However, the influence of 
bimodal grain size distribution as a decisive factor has been rarely considered in systematic approach up to date. In this context, the present work was conducted to study the effects of hot deformation conditions on achieving an optimum combination of strength and ductility through bimodal grain size distribution. The investigation was performed by emphasizing the effects of grain size distribution on the work hardening behavior of an advanced high strength steel holding the capability of twipping and tripping processes.

\section{Experimental Procedure}

The experimental material was received in hot rolled condition holding the chemical composition of Fe-21Mn-1.6Al-2.5Si-0.01C. The as received material was machined to proper workpieces to apply the predetermined hot rolling cycles. The workpieces were rolled down to $30 \%$ and $60 \%$ thickness reduction through 1 pass at different temperatures $\left(1000^{\circ} \mathrm{C}, 1100^{\circ} \mathrm{C}\right.$, and $1200^{\circ} \mathrm{C}$ ) followed by air cooling. These were performed to ensure the occurrence of restoration processes (in particular dynamic and static recrystallization) and accordingly to generate the microstructures composing of coarse and fine grains. As was mentioned, the size and distribution of the grains might directly influence the material capability to twinning and martensitic transformation under the subsequent room temperature deformation. To investigate the microstructures of the hot rolled materials, the workpieces were sectioned in the rolling $(\mathrm{RD})$ and transverse (TD) directions, grounded and electro-polished. The microstructures were optically characterized using $4 \%$ Nital etchant. To assess the room temperature mechanical properties of the hot rolled materials, the tensile tests were conducted according to ASTM E8M standard [37] under the initial strain rate of $0.001 \mathrm{~s}^{-1}$ using a Santam-20KN universal testing machine holding a load accuracy of $1 \mathrm{~N}$. In order to differentiate between $\varepsilon$ martensite and fine twins, a tensile test was 
interrupted at logarithmic strain of 0.27 . The corresponding microstructure was characterized through electron backscattered diffraction (EBSD). EBSD scan was performed in a JSM-7001F field emission scanning electron microscope (FESEM) equipped with Channel 5 system (HKL Technology), operating at $20 \mathrm{kV}$ with specimens tilted $70^{\circ}$. The fracture surfaces and the corresponding underneath microstructures of the tensile specimens were also analyzed using scanning electron microscopy (SEM PhilipsXL30). The phase identification analysis by X-ray diffraction (XRD) was also carried out utilizing a Philips X'Pert PRO apparatus with a rotating copper anode $(\mathrm{Cu} \mathrm{K} \alpha 1)$ radiation and wave length of $\lambda=1.5406 \dot{A}$.

\section{Results and discussion}

\subsection{Microstructural evolution}

The optical microstructures of the experimental material after 7 min soaking (just prior to the hot rolling) at 1000,1100 and $1200^{\circ} \mathrm{C}$ are shown in Fig. 1. As is observed, the average grain size increases monotonically from $55 \pm 3$ to $90 \pm 2 \mu \mathrm{m}$ and finally reaches $160 \pm 4 \mu \mathrm{m}$ by raising the temperature. The frequency of annealing twins is also increased by temperature.

The developed microstructures after hot rolling-air cooling treatments are depicted in Fig. 2. As is observed, at all deformation conditions the microstructures are partially refined, where a combination of coarse and fine grains is recognized. The latter is so called as bimodal grain size microstructure. The microstructural refinement is attributed to the activation of recrystallization processes, which have been well addressed in the previous works employing quantitative and qualitative approaches $[23-25,38]$. Considering the main subject of the present work and to well trace the quantity of bimodal grain size distributions, the variations of frequency vs. mean grain size are presented in Fig. 3. As is clearly realized, the distribution of grain size is more 
inhomogeneous at higher rolling temperatures. For instance, at $1200{ }^{\circ} \mathrm{C}$ and $60 \%$ thickness reduction, the grain size varies between 2 to $225 \mu \mathrm{m}$, holding the highest frequency in the range of $2-15 \mu \mathrm{m}$. In fact, under the aforementioned rolling conditions the stored energy is not high enough to activate the recrystallization through the whole microstructure. Therefore, the formation (nucleation and growth) of recrystallized grains is confined to the specified regions. Moreover, the high temperature during deformation caused the initial un-recrystallized grains to be coarsen. As the grain size distribution in initial microstructures (after soaking/before rolling, Fig. 1) is almost homogeneous, the occurrence of grain growth close to the fine grains is clearly characterized.

To be more precise, the bimodal grain size distribution was quantified and represented in Table 1. The austenite grain sizes were measured from the coarse grain regions $\left(D_{c}\right)$, fine grain regions $\left(D_{f}\right)$ and considering both regions simultaneously $\left(D_{\text {avg }}\right)$. The degree of bimodality was quantified employing: (i) the ratio of average grain sizes between the coarse and fine grain regions $\left(D_{c} / D_{f}\right)$, (ii) the difference in average grain sizes between coarse and fine grain regions $(\Delta D)$, and (iii) the difference in average grain sizes between the coarse and fine grain regions divided by the average grain size measured considering both coarse and fine grain regions $\left(\Delta D / D_{\text {avg }}\right)$. As is well traced, the higher the rolling temperature and the lower the thickness reduction, the greater the degree of grain size bimodality. Based on the quantified bimodality factors, three different regions of low, medium and high bimodality are characterized which would definitely affect the subsequent capability of the material to be work harden during straining.

\subsection{Mechanical properties at room temperature}

The flow behaviors of the hot rolled material were defined by tensile testing at room temperature under the initial strain rate of $0.001 \mathrm{~s}^{-1}$ (Fig. 4). As is seen, suitable combinations of 
high strength and high ductility with the formability indexes between 28000-63000 MPa.\% are achieved through the applied hot rolling-air cooling treatments. As is expected, the room temperature mechanical properties are significantly influenced by the rolling temperature and thickness reduction. The yield and ultimate tensile strength and also the elongation to fracture values are extracted and depicted in Fig. 5. The yield stress is significantly decreased by increasing the temperature. This is rationalized considering Hall-Petch effects [39], i.e. relying on the higher mean grain size of the materials rolled at $1200^{\circ} \mathrm{C}$ in comparison to that of 1100 and $1000^{\circ} \mathrm{C}$. In spite of yield stress decreasing trend, the tensile stress and ductility are generally increased by increasing the rolling temperature. This is justified based on the hardening capability of the material processed at various conditions. In order to assess the processed materials hardening behavior at a glance, the variations of yield to tensile strength ratio corresponding to different rolling temperatures and rolling thickness reduction are presented in Fig. 5c. As is observed, the obtained values stand below the threshold ratio (i.e. <0.7), which provides a safety margin against failure in the post-yield area [32]. This represents the high work hardening capacity of hot rolled materials at room temperature. In addition, a decreasing trend of yield to tensile ratio is recognized as the rolling temperature increases and the thickness reduction decreases. These is discussed precisely in the following sections.

\subsubsection{Work hardening behavior}

In this study, the Considere's criterion was used to predict the onset of necking from the point of intersection between the true stress and work hardening curves, as is represented in Fig. 6. As is observed, a very little necking occurs and the fractured is reached suddenly just beyond the strain limit shown by point A, B, and C. The typical strain hardening behavior of the materials 
deformed at 1100 and $1200^{\circ} \mathrm{C}$ is divided to 4 stages. At the initial periods of plastic deformation, the strain hardening rate decreases rapidly (Stage A) and then declines slightly down to the critical strain required to initiate the austenite to martensite transformation and twinning (Stage B). The work hardening is enhanced in the third stage (Stage C). The suggested work hardening mechanism in this region is martensitic transformation. In addition, the primary/secondary twinning and their interactions may raise the rate of work hardening in the specified deformation condition. However, as is well understood $[7,8]$, the contribution of the twinning and tripping in full austenitic microstructures would dependent upon the grain size distribution; this will be explained afterwards. In the final periods of plastic deformation (Stage D) the microstructure is saturated and the hardening rate decreases abruptly. Interestingly, in the work hardening curve of the specimen rolled at $1000^{\circ} \mathrm{C}$ only 3 stages are characterized; the Stage C appears to be eliminated.

Considering the calculated stacking fault energy of the experimental material through Olsen and Cohen model [40], which is around $18-22 \mathrm{~mJ} / \mathrm{m}^{2}$ at $25^{\circ} \mathrm{C}$, the present material is prone to the simultaneous occurrence of twinning and martensitic transformation at room temperature. In order to confirm the occurrence of martensitic transformation, the X-ray patterns of the deformed specimens are shown in Fig. 7. The strain induced transformation of austenite to martensite during room temperature deformation may be proceeded through three ways [43,45]. These ways are $\gamma \rightarrow \varepsilon, \gamma \rightarrow \alpha^{\prime}$, and $\gamma \rightarrow \varepsilon \rightarrow \alpha^{\prime}$. The volume fraction of each phases are shown in Fig. 8. The main issue is the fact that the hardening effect of $\varepsilon$ martensite, achieved by strain induced $\gamma \rightarrow \varepsilon$ transformation, is relatively weaker than that of $\alpha^{\prime}$ after $\gamma \rightarrow \alpha^{\prime}$ transformation. As is observed, for $30 \%$ thickness reduction, the amount of $\alpha^{\prime}$ martensite is raised by increasing the temperature from $1000^{\circ} \mathrm{C}$ to $1100^{\circ} \mathrm{C}$, but is decreased in the specimen treated at $1200^{\circ} \mathrm{C}$. But for $60 \%$ thickness reduction, the amount of $\alpha^{\prime}$ martensite is monotonically increased by temperature. The variation 
of the overall martensite fraction $\left(\alpha^{\prime}+\varepsilon\right)$ also follows the same increasing trend. This is consistent with the observed variation in mean grain size and its distribution. As was noted, the mean grain size and the bimodality of grain size distributions are increased by raising the rolling temperature. In fact, it appears that the formation of strain induced martensite in coarse grains would be easier in comparison to that of fine grains. Therefore, the amounts of martensite formed in the specimens rolled at 1100 and $1200^{\circ} \mathrm{C}$ are higher than that of $1000^{\circ} \mathrm{C}$ ones. It is worth noting that the higher amount of martensite in former cases can be considered as an evidence of their higher capability to work hardening during further straining, i.e. the higher ultimate strength and elongation to fracture values. Some minor deviations from the discussed trend can be attributed to the contribution of mechanical twinning to induce plasticity at various processing conditions. For instance, despite the higher volume fraction of $\alpha^{\prime}$ martensite in the specimen rolled at $1100^{\circ} \mathrm{C} / 30 \%$ compared to that of $1200^{\circ} \mathrm{C} / 30 \%$, the latter possesses higher ductility values. This is reasoned considering the higher twinning potential in coarse austenite grains, which their fraction is higher in specimens treated at $1200^{\circ} \mathrm{C}$. Considering the higher bimodality factor, the frequency of fine grains in the specimens treated at $1200^{\circ} \mathrm{C} / 30 \%$ is also more than that of $1100^{\circ} \mathrm{C} / 30 \%$ ones. This would retard the twin formation into higher strain levels. It is generally believed that the deformation of fine grains is assisted by martensitic transformations, but the coarse grains are assisted by twinning.

In order to clarify the occurrence of twinning and martensitic transformation, the SEM images of the developed microstructures are considered (Fig. 9). As is recognized, the prevailing plastic deformation mechanism in the materials processed at $1000^{\circ} \mathrm{C}$ (Fig. 9a) is martensitic transformation. The $\alpha^{\prime}$-martensite forms at the intersections of $\varepsilon$ ones (indicated by red arrows), where the high amount of stress is concentrated. As is well known, the source of both $\varepsilon$ martensite 
and deformation twins is similar because they both formed along stacking faults. Therefore, EBSD analysis can be used to differentiate the $\varepsilon$ martensite and deformation twins. However, the high dislocations density of the microstructures at the fracture strain makes the differentiation impossible. Therefore, the phase map of the microstructure which has been rolled at $1000^{\circ} \mathrm{C}$ and tensile tested up to the logarithmic strain of 0.27 is presented in Fig. $9 \mathrm{~g}$. The green and gray colors show $\varepsilon$ martensite and red and the blue one are $\alpha^{\prime}$-martensite and austenite, respectively. It is worth noting that the $D_{f}$ (average grain size of fine grain regions $(<15 \mu \mathrm{m})$ ), $D_{c}$ (average grain size of coarse grain regions), and $D_{\text {avg }}$ (numerical average grain size) in the microstructures of the materials rolled at $1000^{\circ} \mathrm{C}$ are positioned in the range of $8-9,19-23$, and $11-16 \mu \mathrm{m}$, respectively (Table 1 ). The fine grains suppress the formation of twins since the mechanical twinning is triggered just where the planar dislocation piles up reach to the necessary level. This suppression is very sensitive to the grain size where it goes lower than $15 \mu \mathrm{m}[41,42]$. In addition, the deformation twinning defines the length of work hardening region (since it enhances the ductility values) and martensitic transformation indicates the magnitude of hardening. Accordingly, since the deformation twinning is suppressed in finer grain sizes, the elimination of Stage $C$ in hardening curve of the materials deformed at $1000^{\circ} \mathrm{C}$ appears to be rationalized (refer to Fig. 6).

Since the bimodality factor is significantly increased by hot rolling at 1100 and $1200^{\circ} \mathrm{C}$, the deformation twinning and strain induced martensite transformation have the necessary activation energy to form in coarser grains. Consequently, the presence of mechanical twins in Figs. 9b and 9c (indicated by the arrows) is rationalized. In comparison with $1100^{\circ} \mathrm{C}$, the secondary deformation twins crossing the primary ones are seen in the tensile specimens of the materials rolled at $1200{ }^{\circ} \mathrm{C}$ (Figs. 9c, and 9e). For further clarification, the higher magnification images of secondary twins and primary/secondary twins intersections are depicted in Fig. 10. 
Another main point is the $\alpha^{\prime}$-martensite formation at the twin bands interfaces, which are considered as high energy preferred sites for martensite nucleation (Fig. 10a). Owing to the simultaneous formation of martensite and twins along with their interactions, the work hardening capability of the experimental material is raised and higher elongation to fracture is achieved in the materials processed at 1100 and $1200^{\circ} \mathrm{C}$.

\subsubsection{Fractography}

The SEM images of tensile specimens' fracture surfaces are shown in Fig. 11. The presence of deep and shallow dimples with different size and depth beside the cleavage denotes a mixture mode of ductile and brittle fracture. This coincides with high ductility and high strength values obtained at various deformation conditions. For instance, the contribution of dimpling is well higher in the fracture surface of the materials processed at $1200^{\circ} \mathrm{C}$ (Figs. 11c, 11f). The mechanism of ductile fracture is believed to be micro-voids formation at the grain boundaries and triple junctions. Moreover, dimple fracture is partially replaced by quasi-cleavage fracture due to the appearance of martensitic laths by increasing the martensite portion. Another evidence of high ductility values would be the presence of strain markings, known as ripple lines, on the walls of some large dimples, which are indicated in Fig. 12. Finally, it can be concluded that the characteristics of the fracture surface logically represent the tensile behavior of the processed materials.

The ultra fine size dimples and their equiaxed shape and discontinuous distribution, i.e. the cavitation behavior of the experimental material, are introduced as the main factors which influence the necking retardation phenomena. Equiaxed and fine dimples indicate that the cavitation starts at the final stage of tensile deformation. This is justified considering the 
occurrence of twinning and martensite formation even at the early stages which enhances the hardening capability of the material. Bouaziz et al [44] showed that in high Mn steels with twinning ability, no necking was observed due to delay in the formation of voids or integration avoidance of them during the tensile test. They found that in comparison with conventional steels, the void content is much lower in the TWIP steels. Therefore, it seems that void formation and high hardening capability result in high ductility values and prevention of necking.

\section{Conclusion}

The main conclusions of the present work are summarized as follows. The microstructures of the experimental material after hot rolling at various conditions showed different levels of bimodal grain size distributions (bimodality) due to the occurrence of partial recrystallization. The mean grain size and bimodality were increased by increasing the rolling temperature and decreasing the thickness reduction. These significantly influenced the activation of martensitic transformations and mechanical twinning in subsequent tensile deformation at room temperature. This in turn affected the work hardening capacity of the material. The simultaneous operation of martensite formation, mechanical twinning and their interactions led to the appearance of the 4 stages hardening behavior in the case of materials rolled at 1100 and $1200^{\circ} \mathrm{C}$. However, the rapid hardening region was eliminated in the work hardening behavior of the material rolled at $1000^{\circ} \mathrm{C}$ where the distribution of grain size was more homogenous and the grain size bimodality was low. These were attributed to the grain size effect on the probability of twinning and tripping in rolled microstructures. It was discussed that the mechanical twinning would define the length of the work hardening region and the transformation of austenite-to-martensite would indicate the magnitude of strain hardening. 


\section{References}

[1] S. Patra, Sk. Md. Hasan, N. Narasaiah, D. Chakrabarti, Mater. Sci. Eng. A 538 (2012) 145- 155.

[2] Y.M. Wang, M.W. Chen, F.H. Zhou, E. Ma, Nature 419 (2002) 912-915.

[3] R. Song, D. Ponge, D. Raabe, J.G. Speer, D.K. Matlock, Mater. Sci. Eng. A 441 (2006) 1-17.

[4] J. Gil Sevillano, J. Aldazabal, Scripta Mater. 51 (2004) 795-800.

[5] M.C. Zhao, F. Yin, T. Hanamura, K. Nagai, A. Atrens, Scripta Mater. 57 (2007) 857-860.

[6] H. Qiu, R. Ito, K. Hiraoka, Mater. Sci. Eng. A 435-436 (2006) 648-652.

[7] G.J. Fan, H. Choo, P.K. Liaw, E.J. Lavarnia, Acta Mater. 54 (2006) 1759-1766.

[8] H. Jin, D.J. Lloyd, Scripta Mater. 50 (2004) 1319-1323.

[9] D.T. Pierce, J.A. Jiménez, J. Bentley, D. Raabe, J.E. Wittig, Acta Mater. 100 (2015) 178-190.

[10] O. Grässel, L. Krüger, G. Frommeyer, L.W. Meyer, Int. J. Plasticity 16 (2000) 1391-1409.

[11] D. Barbier, N. Gey, S. Allain, N. Bozzolo, M. Humbert, Mater. Sci. Eng. A 500 (2009) 196-206.

[12] A. Saeed-Akbari, L. Mosecker, A. Schwedt, W. Bleck, Metall. Mater. Trans. A 43 (2012) 1688-

1704.

[13] A. Saeed-Akbari, A. Schwedt, W. Bleck, Scr. Mater. 66 (2012) 1024-1029.

[14] B.C. De Cooman, O. Kwon, K.-G. Chin, J. Mater. Sci. Technol. 28 (2012) 513-527.

[15] O. Bouaziz, S. Allain, C.P. Scott, P. Cugy, D. Barbier, Curr. Opin. Solid State Mater. Sci. 15 (2011) $141-168$.

[16] S. Curtze, V.T. Kuokkala, Acta Mater. 58 (2010) 5129-5141.

[17] H. Ding, H. Ding, D. Song, Z. Tang, Ping Yang, Mater. Sci. Eng. A 528 (2011) 868-873.

[18] F. Hiroshi, K. Tetsuya, Mater. Trans. JIM 33 (1992) 243-251.

[19] G. Frommeyer, U. Brux, P. Neumann, ISIJ Int. 43 (2003) 438-446.

[20] C.C. Hyoung, K.H. Tae, C.S. Hong, W.C. Yong, Scripta Mater. 40 (1999) 1171-1177.

[21] D.C. Ludwigson, Metall. Trans. 2 (1971) 2825-2828.

[22] S. Kazunori, I. Michiyuki, H. Yoshihiko, I. Yasunobu, ISIJ Int. 29 (1989) 868-876.

[23] A. Marandi, R. Zarei-Hanzaki, A.Zarei-Hanzaki, H.R.Abedi, Mater. Sci. Eng. A 607 (2014) 397-408.

[24] A. Marandi, A. Zarei-Hanzaki, N. Haghdadi, M. Eskandari, Mater. Sci. Eng. A 554 (2012) 72-78.

[25] M. Eskandari, A. Zarei-Hanzaki, A. Marandi, Mater. Des. 39 (2012) 279-284.

[26] Pooriya Dastranjy Nezhadfar, Abbas Zarei-Hanzaki, SeokSuSohn, Hamid Reza Abedi, Materials

Science \& Engineering A 665 (2016) 10-16.

[27] I. Gutiérrez-Urrutia, S. Zaefferer, D. Raabe, Mater. Sci. Eng. A 527 (2010) 3552-3560.

[28] G.N. Haidemenopoulos, N.Aravas, I.Bellas, Mater. Sci. Eng. A 615 (2014) 416-423.

[29] Mohammad Moallemi, Abbas Zarei-Hanzaki, Ahmad Mirzaei, Journal of Materials Engineering and Performance 24 (2015) 2335-2340. 
[30] H. Mirzadeh, Jose Maria Cabrera, Abbas Najafizadeh, Acta Mater. 59 (2011) 6441-6448.

[31] Alireza Mohamadizadeh, AbbasZarei-Hanzaki, Hamid Reza Abedi, Mechanics of Materials 95 (2016) 60-70.

[32] A.R. Khalesian, A. Zarei-Hanzaki, H.R. Abedi, F. Pilehva, Mater. Sci. Eng. A 596 (2014) 200-206.

[33] J. Hajkazemi, A.Zarei-Hanzaki, M.Sabet, S.Khoddam, Mater.Sci.Eng.A 530 (2011)233-238.

[34] N. Cabanas, N.Akdut, J.Penning, B.C.DeCooman, Mater.Trans.A 37 (2006) 3305-3315.

[35] A.S.Hamada, L.P.Karjalainen, Mater.Sci.Eng.A 528 (2011) 1819-1827.

[36] A.Zarei-Hanzaki, P.D.Hodgson, S.Yue, Mater.Trans.A 28 (1997) 2405-2414.

[37] ASTM E8. Standard test methods for tension testing of metallic materials. Annual book of ASTM standards 3 (2004) 1.

[38] M. Eskandari, A. Zarei-Hanzaki, J.A. Szpunar, M.A. Mohtadi-Bonab, A.R. Kamali, M. NazarianSamani, Mater.Sci.Eng.A 615 (2014) 424-435.

[39] Taekyung Lee, Motomichi Koyama, Kaneaki Tsuzaki, You-Hwan Lee, Chong Soo Lee, Materials Letters 75 (2012) 169-171.

[40] P.H. Adler, G.B. Olsen, and W.S. Owen, Metall. Trans. A 17 (1986) 1725-37.

[41] G. Dini, A. Najafizadeh, R. Ueji, S.M. Monir-Vaghefi, Materials and Design 31 (2010) 3395-3402.

[42] G. Dini, A. Najafizadeh, S.M. Monir-Vaghefi, R. Ueji, J. Mater. Sci. Technol., 2010, 26(2), 181-186.

[43] Y.F. Shen, X.X. Li, X. Sun, Y.D. Wang, L. Zuo, Materials Science and Engineering A 552 (2012) 514- 522 .

[44] D. Fabrègue, C.Landron, O.Bouaziz, E.Maire, Materials Science \& Engineering A 579 (2013) 9298.

[45] Y.F. Shen, Y.D. Wang, X.P. Liu, X. Sun, R. Lin Peng, S.Y. Zhang, L. Zuo, P.K. Liaw, Acta Materialia 61 (2013) 6093-6106. 


\section{Materials Science and Engineering A \\ Ref. No.: D-16-02527R1}

Manuscript Title: The effects of bimodal grain size distributions on the work hardening behavior of a TRansformation-TWinning Induced Plasticity steel

\section{Dear Editor}

Many thanks for your valuable comments on the content of our manuscript. We have modified the manuscript based on the reviewers' comments, and the detailed corrections are listed below point by point:

\section{Response to reviewer \#1:}

By using OM, SEM and uniaxial tensile techniques, the effects of bimodal grain size distributions on the mechanical properties of a newly developed TRansformation-Twinning induced plasticity (TRIP/TWIP) steel were investigated. Some results are new, very interesting and the quality of the manuscript has been improved significantly after major revisions. However, revision is necessary before publication:

\section{Comment 1:}

(1) Fig.9a: How can you distinguish $\varepsilon$-martensite from fine twin and/or <alpha>-martensite by using SEM? Please defend your point in the corresponding text.

\section{Reply to comment 1:}

The morphology of $\alpha^{\prime}$ martensite and $\varepsilon$ martensite is different. The $\varepsilon$-martensite has blade like morphology and its blades are parallel with each other. But the morphology of strain induced $\alpha^{\prime}$ martensite is blocky, when it forms in the intersections of $\varepsilon$ martensite. Where the $\alpha^{\prime}$-martensite forms directly from austenite, its morphology can be blocky and/or blade like, but its blades are not parallel and have intersections with each other.

As is well known, the source of both $\varepsilon$ martensite and deformation twins is similar because they both formed along stacking faults. Therefore, EBSD analysis can be used to differentiate the $\varepsilon$ martensite and deformation twins. However, the high dislocations density of the microstructures at the fracture strain makes the differentiation impossible. Therefore, the phase map of the 
microstructure which has been rolled at $1000^{\circ} \mathrm{C}$ and tensile tested up to the logarithmic strain of 0.27 is presented in Fig. 9g. The related sentences have been added in various section of the revised manuscript:

\section{Comment 2:}

(2) In page 10, you declared that "The transformation of austenite to martensite during room temperature straining may be proceeded through three schemes...".

In this part and the related descriptions in whole text, how can you tell it is three stages? How can you tell it depends on stress or strain by using your present technique?

Some proper explanations and proper references must be provided to strengthen your point:

[1] Mater Sci Eng A, 552(2012)514-522.

[2] Acta Mater, 61(2013) 6093-6106.

\section{Reply to comment 2:}

The structure of the aforementioned sentence seems to be confusing. We mean that the transformation of austenite to martensite under the imposed strain may be proceed through three different ways of $\gamma \rightarrow \varepsilon, \gamma \rightarrow \alpha^{\prime}$, and $\gamma \rightarrow \varepsilon \rightarrow \alpha^{\prime}$. Based on this assumption, then the amounts of austenite and strain induced $\alpha^{\prime}$ and $\varepsilon$ martensite are measured and shown in Fig. 8. Therefore we have corrected the manuscript as is follows (page 8):

"The strain induced transformation of austenite to martensite during room temperature deformation may be proceeded through three ways $[43,45]$. These ways are $\gamma \rightarrow \varepsilon, \gamma \rightarrow \alpha^{\prime}$, and $\gamma \rightarrow \varepsilon \rightarrow \alpha^{\prime}$. The volume fraction of each phases are shown in Fig. 8."

The proposed papers have been also found so helpful and have been referenced through the text.

\section{Response to reviewer \#2:}

This is an interesting paper, but the manuscript has some major/minor deficiencies that need to be addressed before publication. 


\section{Comment 1:}

Authors examined the effect of grain coarsening under static annealing prior hot rolling and the formation of necklace structure during hot rolling on tension behavior of low carbon TWIP-TRIP steel. Bimodal grain distribution is one structural parameter. The second and important structural parameter is density of lattice dislocations. I strongly recommend authors to obtain the density of lattice dislocations by TEM technique and present these data in the manuscript. It is not a problem since we can expect a highest value of $10^{14} \mathrm{~m}^{-2}$ for hot rolling at $1000^{\circ} \mathrm{C}$.

\section{Reply to comment 1:}

As you noted, high values of dislocation density $\left(\sim 10^{14} \mathrm{~m}-2\right)$ are expected for the microstructures deformed at various deformation conditions. Accordingly, a minor difference may be achieved. In addition, the amount of dislocation density would increase during subsequent tensile testing and makes difficult to identify its effect on the work hardening behavior of the processed materials. The present authors aimed to discuss about the individual effect of dislocation density through TEM study in future works.

\section{Comment 2:}

Authors have to subdivide the $3 \mathrm{~d}$ section to Results and Discussion as separate sections. Work hardening has to be considered to Discussion with the aim to explore the termination of ability to plastic deformation. For this purpose I recommend authors to carry out Considere analysis. For this purpose it is necessary to plot true stress - true strain curves in addition Fig.4. and indicate the Considère criterion conditions by dashed line in Fig.6. Please, discuss the onset of plastic flow instability in connection with ductile fracture.

\section{Reply to comment 2:}

The Considere analysis was employed to discuss about initiation of plastic yielding; we discuss about it in page 8 and as is follows: "In this study, the Considere's criterion was used to predict the onset of necking from the point of intersection between the true stress and work hardening curves, as is represented in Fig. 6. As is observed, a very little necking occurs and the fractured is reached suddenly just beyond the strain limit shown by point A, B, and C." 
Moreover, we discussed about the onset of plastic flow instability in connection with ductile fracture in the final part of the manuscript (page 12). The added sentences are as follows:

"The ultra fine size dimples and their equiaxed shape and discontinuous distribution, i.e. the cavitation behavior of the experimental material, are introduced as the main factors which influence the necking retardation phenomena. Equiaxed and fine dimples indicate that the cavitation starts at the final stage of tensile deformation. This is justified considering the occurrence of twinning and martensite formation even at the early stages which enhances the hardening capability of the material. Bouaziz et al [44] showed that in high Mn steels with twinning ability, no necking was observed due to delay in the formation of voids or integration avoidance of them during the tensile test. They found that in comparison with conventional steels, the void content is much lower in the TWIP steels. Therefore, it seems that void formation and high hardening capability result in high ductility values and prevention of necking. "

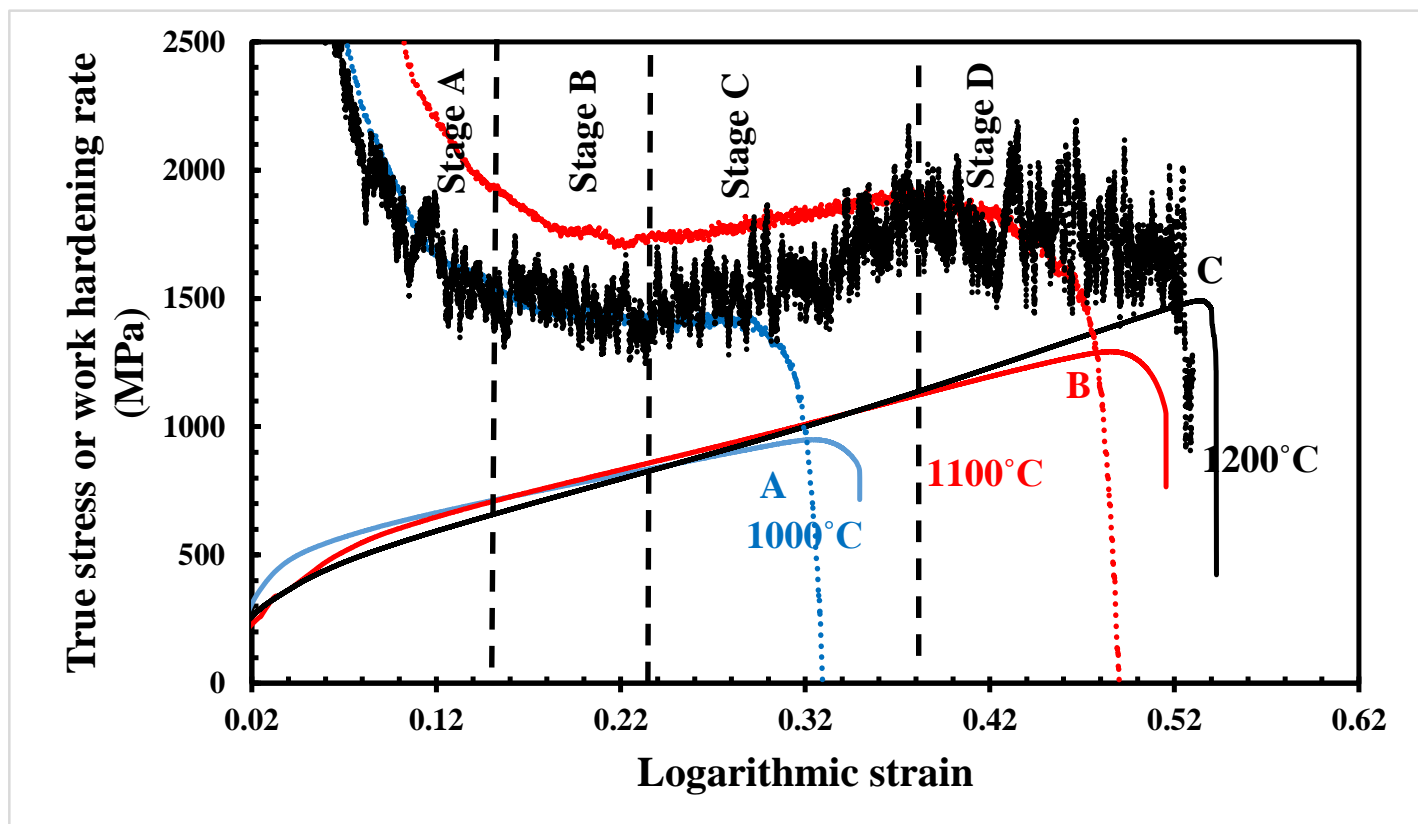




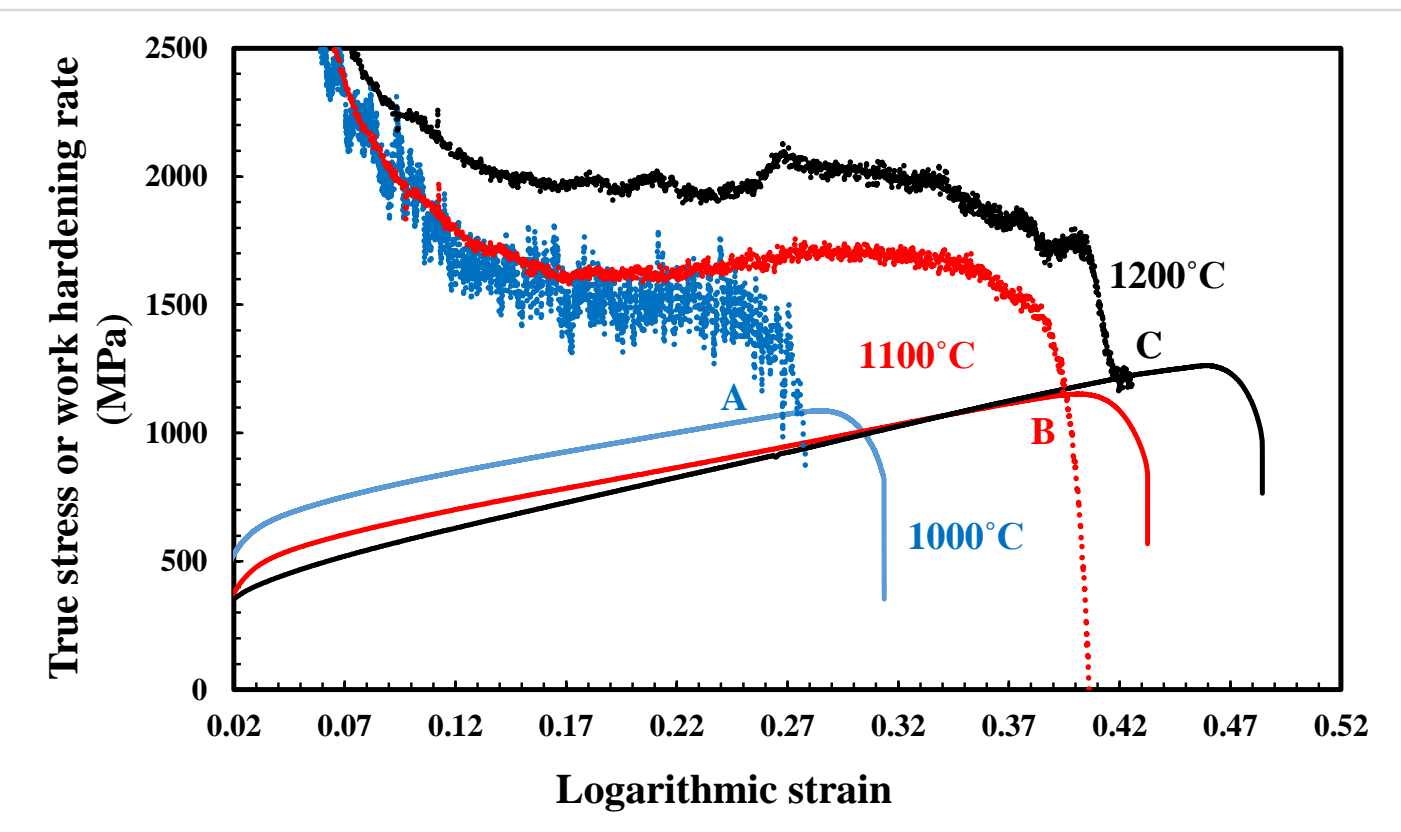

Fig. 6. The true stress- logarithmic strain and the work hardening behavior during tensile testing of the hot rolled experimental material at different conditions: (a) 30\%, and (b) 60\% thickness reduction.

\section{Comment 3:}

Please, revise the following sentence "the deformation twinning and strain induced martensite transformation possess the necessary activation energy to form in coarser grains" at Page 10. It is well known (see J.W. Christian, S. Mahajan, Prog. Mater. Sci. 39 (1995) 1-157) that critical stress for twinning is inversely dependent on grain size and, therefore, grain coarsening promotes both twinning and, therefore, strain-induced martensitic transformation, since martensite laths nucleate at deformation twin boundaries, mostly (N. Nakada, H. Ito, Y. Matsuoka, T. Tsuchiyama, S. Takaki, Acta Mater. 58 (2010) 895-903.).

\section{Reply to comment 3:}

We mean that grain coarsening promotes both deformation twinning and martensitic transformation and our sentence structure seems to be confusing. Therefore we have corrected this sentence in the manuscript (page 10): 
"The deformation twinning and strain induced martensite transformation have the necessary activation energy to form in coarser grains."

\section{Optional recommendations:}

There are also two optional recommendations. First, replace optical micrographs in Figs.1 and 2 by misorientation maps reconstructed from EBSD data. Second, it is reasonable to present TEM micrographs with appropriate diffraction patterns for twins and hcp and bcc martensites in addition to Figs.9 and 10. Third, please, decrease the number of fractographic pictures in Fig. 11 and provide higher magnification. It seems that dimple fracture is partially replaced by quasi-cleavage fracture due to the appearance of martensitic laths with increasing martensite portion, is not it?

\section{Reply to Optional recommendations:}

The EBSD and TEM analysis is very useful for this project but we don't have these equipment in our country. However we try to collaborate with other researchers in other countries to represent the EBSD and TEM analysis in our future papers. But about the third recommendation, we decreased the fractographic images to 4 images and their higher magnifications were eliminated. Moreover, it is right that dimple fracture is partially replaced by quasi-cleavage fracture due to martensitic laths with increasing martensite portion and as is seen in the Fig. 11 the quasi-cleavage shapes is increased with increasing the martensite portion. Therefore we added a sentence to the manuscript (page 11) as is followed:

"Moreover, dimple fracture is partially replaced by quasi-cleavage fracture due to the appearance of martensitic laths by increasing the martensite portion."

The revised version of the paper has been resubmitted to the journal. All of the changes made to manuscript have been highlighted clearly.

[1] S. Martin, C. Ullrich, D. Rafaja, Deformation of Austenitic CrMnNi TRIP/TWIP Steels: Nature and Role of the $\varepsilon^{-}$-martensite, Materials Today: Proceedings 2S ( 2015 ) S643 S646. 
[2] Jee-Hyun Kang, Tobias Ingendahl,Wolfgang Bleck, A constitutive model for the tensile behaviour of TWIP steels: Composition and temperature dependencies, Materials and Design 90 (2016) 340-349.

Sincerely Yours,

Abbas Zarei-Hanzaki

Corresponding Author 